\title{
Pilot study: Neuropsychological association of orbitomedial and dorsolateral executive functions in children with behavioral problems
}

\author{
Ángela M. Polanco-Barreto* and Edgar A. Bulla \\ Grupo de psicología ciencia y tecnología, Corporación Universitaria Iberoamericana, Bogotá, Colombia
}

\begin{abstract}
Objective: This proposal addresses the neuropsychological characterization of dorsolateral and orbitomedial executive functions in children with behavioral problems, to identify the functioning level of the cognitive skills associated with this brain area. Materials and methods: The Latin American version of Swanson, Nolan, and Pelham IV scale was applied for the cutoff point of the behavioral difficulties and the Neuropsychological Assessment Battery of Executive Functions (II) with orbitomedial and dorsolateral scales. Sample: The sample was 71 in-school students (43 girls and 28 boys between ages 8 and 14). Results: There is evidence of association of the group under analysis with difficulties in orbitomedial executive skills (in Stroop A [time], and Stroop B [time]) and dorsolateral executive skills (in Semantic Classification [time]). Conclusions: The fullness and efficacy of executive functions dependent on the dorsolateral cortex will depend on the maturity development of the orbitomedial cortex.
\end{abstract}

Key words: Prefrontal cortex. Executive functions. Behavior.

\section{Estudio piloto: Asociación neuropsicológica de funciones ejecutivas de tipo orbitomedial y dorsolateral en niños con problemas de comportamiento}

\section{Resumen}

Objetivo: Esta propuesta aborda la caracterización neuropsicológica de funciones ejecutivas de tipo dorsolateral y orbitomedial en niños con problemas de comportamiento, para identificar el nivel de funcionamiento de las habilidades cognitivas asociadas con estas áreas del cerebro. Materiales y métodos: Se aplicó la versión latinoamericana de las escalas Swanson, Nolan y Pelham IV, para evaluar las dificultades de comportamiento y la batería de funciones ejecutivas de evaluación neuropsicológica (II) para examinar las áreas orbitomedial y dorsolateral. Muestra: La muestra fue de 71 estudiantes escotares (43 niñas y 28 niños de entre 8 y 14 años). Resultados: Se evidenció la asociación del grupo analizado con dificultades en las habilidades ejecutivas orbitomediales (en Stroop A [tiempo] y Stroop B [tiempo]) y habilidades ejecutivas dorsołaterales (en clasificación semántica [tiempo]). Conclusiones: La plenitud y la eficacia de las funciones ejecutivas que dependen de la corteza dorsolateral dependerá de la madurez y el desarrollo de la corteza orbitomedial.

Palabras clave: Corteza prefrontal. Funciones ejecutivas. Comportamiento.

\section{Correspondence:}

*Ángela María Polanco Barreto

E-mail: angela.polanco@ibero.edu.co

1665-5044/() 2019 Academia Mexicana de creativecommons.org/licenses/by-nc-nd/4.0/)
Date of reception: 22-05-2019

Date of acceptance: 09-07-2019

DOI: 10.24875/RMN. 19000088
Available online: 04-12-2019 Rev Mex Neuroci. 2019;20(6):266-274 www.revmexneurociencia.com
(bttp:// z 


\section{Introduction}

The evolution of the prefrontal cortex (PFC) and the development of the frontal lobe show common variations between old world monkeys, apes, and human beings. Different experimental models have shown in the case of the Rhesus monkeys who can learn detailed expectations of the reward, and in their negative favor they reproduce an emotional behavior of frustration'. This allows to observe that primates and the improvement of the frontal lobe in the control and coordination of cognitive and behavioral processes, manage to organize the behavior according to the environment and the expectations learned, which admit reaching contingencies and, therefore, the organism's adaptation, which has been related to the negative evaluation of the experiences by the amygdala, and the emotional expression or control of it by the orbitofrontal cortex (OFC) and the medial $\mathrm{OFC}^{2,3}$.

Certainly, environmental experiences endow the organism with behavioral patterns necessary to respond to contextual demands; a stress response will be mediated by the cerebral amygdala. However, the neurovegetative substrate that allows a hormonal adaptation according to the stimuli will be mediated by the hypothalamus ${ }^{3,4}$; obeying that the amygdala is a structure that allows the association of different stimuli, reward, and punishment functions. However, thalamic and amygdala afferents, which are shorter and are activated in the first order, send information to the cortex through the thalamocortical connections to provide the organism with more complex meaning; this way, the unification of these sensory and emotional systems, sent to the cortex through the thalamus, allows this continuous feedback to dissociate emotional functions from the exterior and generate patterns of behavior adjusted to the context ${ }^{3,4}$.

According to the aforementioned, the predominant factor or the fundamental role given to the OFC in emotional control and the dorsolateral cortex in the complex planning of behavior toward the environment is evident. It is well known that the efferent pathways of the cerebral cortex toward the thalamus are wider than the afferent ones, because the complex response of behavior will be the specific organized response of the PFC in accordance with the organism's adaptation to environmental contingencies ${ }^{4}$; this way, the medial dorsal nucleus (or dorsomedial nucleus of thalamus) generates projections toward the PFC and provides it with complex functional variables; considering, at a morphological level, that this area of association has a greater number of dendritic spines, which leads to a tigh functional metabolism ${ }^{5}$.

The PFC receives considerable afferents from the thalamus, hypothalamus, limbic system, and different areas of the cerebral cortex, this is how the evolution of this structure in humans has specialized to processes associated with working memory, executive functions, decision-making, the complex function in behavior planning, and discrimination of emotional signals/signaling ${ }^{5}$.

The evolutionary process of the PFC is also well known in other species, such is the case of the albino rat whose medial dorsal nucleus (or dorsomedial nucleus of thalamus) generates projections toward the medial PFC, involving different functions along. With other basal projections such as motor, olfactory, and autonomic visceral patterns, among others. In line with the aforementioned, the different afferent innervations of the PFC (both thalamic and from different regions of the brain) allow neural activation by AMPA receptors or monoamine receptors from the mesencephalic region, generating cortical excitation; this way, dopaminergic innervation in the PFC of primates has been widely studied, as well as its reciprocation with GABAergic neurons that project to the nucleus accumbens (NAC or NAcc), mediating, and in turn inhibitory regulafory functions ${ }^{6}$.

The PFC has serotonergic innervations that come from the raphe nuclei, which apparently helps to mediate the interaction of other neurotransmitters sucbas catecholamines. Clearly, prefrontal or analogous strpuctures are recognized in primates: to a certain degree Goldberg (2001) - picking up on Brodmann's findings - describes that apes such as chimpanzees would have $17 \%$, the gibbon and the macaque (the mohkey of the old world) $8.5 \%$, and the lemur $7 \%$. Nevertheless, the percentage in humans rises to $29 \%$, which recognizes a greater development in structure and in adaptive processes in comparison to other species. It is also known that this association cortex matures fate which is absolutely related to the delay of controt of associated behaviors, such as elaborated language in context and reasoning ${ }^{3}$.

Several models have been proposed to describe-the different components that make up executive functions, sometimes referring to them as an integrated set and at other times as different connectionist structures that allow the development of executive processes with a defined hierarchical structure (such as attentional flexibility, inhibitory control, and working memory) $)^{7}$. Thus, it can be determined that the functions of attention 
receive vital importance since selective attention modulates the flow of information as well as its processing, which in turn allows the consolidation of implicit memory. The theories on the importance of the PFC - already mentioned by Luria posit that dysfunctions in behavior management (e.g., planning, among others), derive from the channeling of such attentional flow as the basis of executive processes; however, comparative studies show differences in their findings suggesting that, possibly, the alternation of different regions is not hierarchized and that, from another perspective, an intertwined collaboration in the present task generates emerging behaviors ${ }^{8,9}$.

Researches show that executive processes respond to coordinated variables of different regions of the PFC that is modulated in accordance with demanding adaptive processes in the environment. The diversity and heterogeneity of the results reveal functions that may have a hierarchical predominance, but this is not the rule, it seems it is an intermodal function closely related by specific connections that evolved due to adaptive needs. Thus, it can be reductionist to assume that the attentional system can be the regulator of the present information flow, in the sense that it is possible for memory to determine which stimuli to target ${ }^{10}$.

Hence, attention presents a complex arrangement consistent with its close relationship with cognitive flexibility, already referred to by Miyake as a component of alternation that needs several systems which, together, allow access to more complex processes; among these are some systems such as: complex neural systems, multimodal, selective filter, hierarchical system, dynamic system, and supervision of mental activity. Clearly, because of this, the infinity of the intertwined subsystems also links other variables that are important to bear in mind when talking about attention, since it is not only a process that begins with awakening or focusing attention but also involves other processes such as orientation, motivation, processing speed or speed of thought, level of consciousness or concentration, among others ${ }^{10,11}$.

Finally, attention, as a tracking mechanism of different environmental events presents fundamental bases in the brain stem by means of the ascending reticular activating system. These projections must reach the frontal association cortex, with the right hemisphere as the largest exponent; this way, the involuntary attentional processes will be characteristic of structures related to the diencephalon and mesencephalon, and the more complex processes that require voluntary attention will be related to cortical association structures. This reflects chemical actions to the prefrontal lobes that allow the maintenance of executive actions, which means that an optimal state of attention will be closely related to other basic processes such as memory. Clearly, injuries or affectations in these areas can generate behaviors contrary to those expected by the PFC, such as perseveration and impulsive actions, difficulty in planningand inadequate organization of behavior, among other ${ }^{92}$.

Following attention, it is important to focus on those contributing processes in the global integrative of executive functions supported by the PFC. The relevance of the substantive actions of social adaptation also depends on the coordination of language, verbal fluen$\mathrm{cy}$, the way the different verbal constructs are coordinated according to a behavior in a specific context,

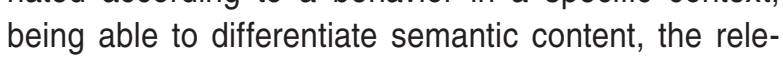
vance of such content in what one wishes to verbafize, the quantity of morphemes, the graphemes used are all characteristic of a coordinated action of the dorsolateral cortex and OFC. However, it is important to bear in mind that this depends on the access to constructs structured and developed by long-term memory ${ }^{3}, 3$

In accordance with the above, it is important to deepen in basic aspects to understand the synergy related to executive functions and those processes that the PFC materializes, since the PFC is the fundamental structure to process information and to generate: Eognitive flexibility, control in interference, and observation of how memory provides all the significant information in complex tasks.

\section{Executive processes and the compromise the dorsolateral cortex and OFC}

Different measurement methods in neurosciences allow to demonstrate affectations in different areas ofthe PFC. According to the evaluation, different compromises can be determined in variables such as cognitive flexibility, attention, and memory. Magnetic resonance imaging (MRIs), computerized axial tomography scan, new tecchnical trends in neuroimaging with a high temporal resolution like the magnetoencephalography, and the \#ew applications created for MRI, have allowed to find fynctional relationships between trauma and control groups ${ }^{14}$.

Such traumatic processes alter the normal devefopment of information processing, cognitive flexibility, and the mastery/domain of interference to different and $r e-$ petitive stimuli in the environment. After a traumatic brain injury low-level processes such as the speed of information processing are affected, manifested in difficulty to focus attention on different environmental stimuli, reducing not only visual tracking processes but 
also the ability to process information and to voluntarily plan answers or possible behaviors in context ${ }^{14}$; it is important to point out that the aforementioned lesions keep correspondence (in an integrated manner) with acquired deficits in cognitive flexibility. The evaluation of these processes relies on the capacity (high-level processes) to regulate interference not only environmental but also proprioceptive, possible emotional information coming from the anterior cingulate cortex, and on the ability to use working memory ${ }^{9}$.

In terms of the acuity of the PFC, there are also features that show the delicate nature of its structures. The abundant connections that innervate the prefrontal area are substantially connected to different subcortical connections; consequently, many explanations are sought to define different pathologies, such as schizophrenia, as mesencephalic lesions during the neurodevelopmental stage, which result in a low mesocortical dopaminergic innervation. This would explain the hypofunction of the cortex and, therefore, the failure in executive control of the striatum (corpus striatum), giving place to the positive symptoms of schizophrenia9.

Certainly, such hypofunction would regulate other chemical processes, such as glutamatergic and GABAergic ones, which help mediate the metabolic activation in the prefrontal lobes. Low activation of the D1 receptors (excitatory dopamine receptor) innervated from the mesencephalic ventral tegmental area would lead to low activity of the dorsolateral PFC (DLPFC or DL-PFC) which, in turn, results in working memory difficulties - observing hypofunctionality in the DLPFC of people with schizophrenia when developing complex tasks ${ }^{15}$.

The PFC, in its delicate structure, has a wide innervation of granular neurons that have a greater representation of connection routes with the medial dorsal nucleus (dorsomedial nucleus of thalamus). Llinás (2002) promotes the vision of this strong interconnection as the one responsible for the determination of consciousness ("the self") and the modification of fixed action patterns; such component, confers important variables such as the control of external stimuli functions ${ }^{16}$. It is also possible to recognize other variables that present alterations during neurodevelopment, some of them characterized by glutamatergic firings in non-NMDA receptors that generate extracellular toxicity and damage of dendritic spines (Díaz and Tirapu, 2017). This added to the synaptic pruning during adolescence - which may be precipitated - and to the difficulties regarding the reorganization of the blood flow ${ }^{17}$.
In this picture, the PFC has striatal and thalamic connections that generate a feedback loop between the globus pallidus, the ventral anterior nucleus, and the ventral lateral nucleus of the thalamus and the caudate nucleus, to which Goldberg (2001) confers importance for its role in the control of movement and characterizes as part of the frontal lobes. These connections of the DLPFC receive entrances from the caudate nucleus, which compromise (destruction or interruption) manifests in pathologies such as primary (subcortical) degenerative dementias, Parkinson, and Huntingtön's disease, or Huntington's chorea. On the other hand, affectations in the basal nuclei (gray) and the PFC can be associated with obsessive-compulsive disorder ${ }^{9_{5}}$.

Within the domain of the executive functions of the dorsolateral cortex is the ones that represent more complexity; this way, decision-making, self-evaluation, and monitoring of continuous performance, and adjustments derived from the performance of multitasking arethe main characteristic of the operation that defines the BLPFC. It is this way - as mentioned above - that the dopaminergic actions have been highlighted: in aspects related to working memory and to the actions described. Certainly, dopaminergic hypofunction remarkably diminishes the quality of such complex actions. On the other hand, the OFC determines variables such as decision-making based on affective states, emotional control, affective, and social behaviors, it allows the evaluation of rewarded behaviors as well as the making of adjustments according to behavior planning and the environment, against the possibility of access to reinforcements; ;his is why it is closely related to the limbic system².

Since the first 5 years of age, the evolutionary dêvelopment of the PFC presents advancements regarding executive functions; however, it is during adolescence (between 12 and 18 years of age) that it shows a bigh level of activation, generating its greatest process of maturation. Perhaps this development is achieved than $\overline{k S}$ to the fact that during adolescence cognitive processesare organized to achieve the legitimacy of a role in the social context and, in turn, find new ways of adaptation and growth of oneself in the environment. All this impliescerebral and cognitive development and maturation ${ }^{18,19}$

These variables allow cognitive control, processes that emerge in behavioral and cerebral development during adolescence. Different researches in the field of MRI-MRFI have allowed to observe this maturational process and thus recognizes that inhibition, working memory, planning, and attention are key in cognitive control. Nevertheless, it goes beyond the execution of tasks or multitasking, it allows to cover concepts such 
as social cognition which are framed in different actions that allow individuals to interact with each other from perception, facial expression, body posture and gaze, representations and the ability to attribute and manipulate mental states when processing social signals ${ }^{19}$.

As previously mentioned, cognitive control allows the temporal ability of organizing behavior, language, and reasoning. This enables the resolution of internal problems that respond to those representations that structure the individual from cognitive and affective integrations. Regarding the external, it refers to the conditions of interaction of the individual with the environment and the culture, dysfunctions of the executive processes associated with the dorsolateral cortex ${ }^{18}$. As previously mentioned, the characteristic dysfunctions in the OFC would present difficulties to the individual when he/she modifies his/her behavior according to contingencies by virtue of access to reinforcers in the social context, and also when representing the mental states of other individuals through the recognition of verbal or non-verbal variables ${ }^{20}$.

In this order of ideas, these dysfunctions are conceptually defined as dysexecutive syndromes. Delgado and Etchepareborda (2013) describe them as prefrontal syndromes, which are subdivided into three groups: dorsolateral prefrontal syndrome; orbitofrontal prefrontal syndrome; and medial prefrontal syndrome or anterior cingulate syndrome, and they attribute specific characteristics to each group. These authors agree with others in that the most common dysexecutive syndromes are related to the DLPFC. Consequently, patients with impairments in this area report difficulties in productivity and creativity but preservation of execution in repetitive tasks that do not represent a challenge although those that require abstraction or need novelty and innovation do present disability?

These alterations hinder an individual's normal process of social adaptation in accordance with the demands of the context and the environment. Thus, difficulty in postponing behaviors and controlling impulses; detailed planning of behavior for the execution of complex activities; recognition of social cues; anticipating contingencies; self-monitoring; and modifying behavior to find reinforcers; all constitute negative sums in the individual that unleash other adjacent pathologies?.

\section{Materials and Methods}

\section{Population}

Evaluation and process was made in general to 71 students ( 43 girls and 28 boys) between 8 and 14 years of age, most of them from public schools (59 students which represent $83 \%$ of the sample) and all of them living in stratus 1-3 (correspond to low strata that house the users with fewer resources). Selection of the sample: the exclusion criteria considered was not being in school at the moment of the study and having either a mild, moderate or profound intellectual disability. The inclusion criteria sample was made up of students schooled; it is important to mention that the minors' legal guardians signed the informed consent, and the minors themselves agreed to participate in the study (informed assent). Moreover, this age was considered as it is the age at which it is expected to perform the chosen tests, especially the orbitofrontal tests.

Which were classified into two groups: on the one hand, children who presented school behavior difficuiflies and, on the other hand, children who did not. The Swanson, Nolan, and Pelham (SNAP) IV scale was applied to determine which group each child belonged to; this scale allows to identify children with significant difficulties at the attentional and behavioral levels by means of motor distress and impulsivity. It is important to clarify that although this scale is applied to identify attention déficit hyperactivity disorder both in school and at home, inthis case, it was used only to determine whether difficulties arose or not, and not to perform a diagnosis as such (because it was not the objective of the research and the conditions for doing so did not take place).

\section{Research type and design}

The study aimed to follow a quantitative approach of a descriptive and explanatory type. It was also cross-sectional since, at a certain moment, it sought to explain the relationship between executive functions (of ethe dorsolateral and orbitomedial type) in children with behavioral difficulties; this was done not only from a theoretical basis but also from the analysis of other researches and the results themselves, highlighting the particularities in its operation and generating comparisons with other groups of children.

\section{Procedure and instruments}

The instruments used: sociodemographic data questionnaire, application of the Latin American version of the SNAP IV scale to determine the cutoff point of children presenting behavioral difficulties from those who do not and application of the Neuropsychological Assessment Battery Executive Functions Module (II), orbitofrontal (measures inhibition and regulation of 


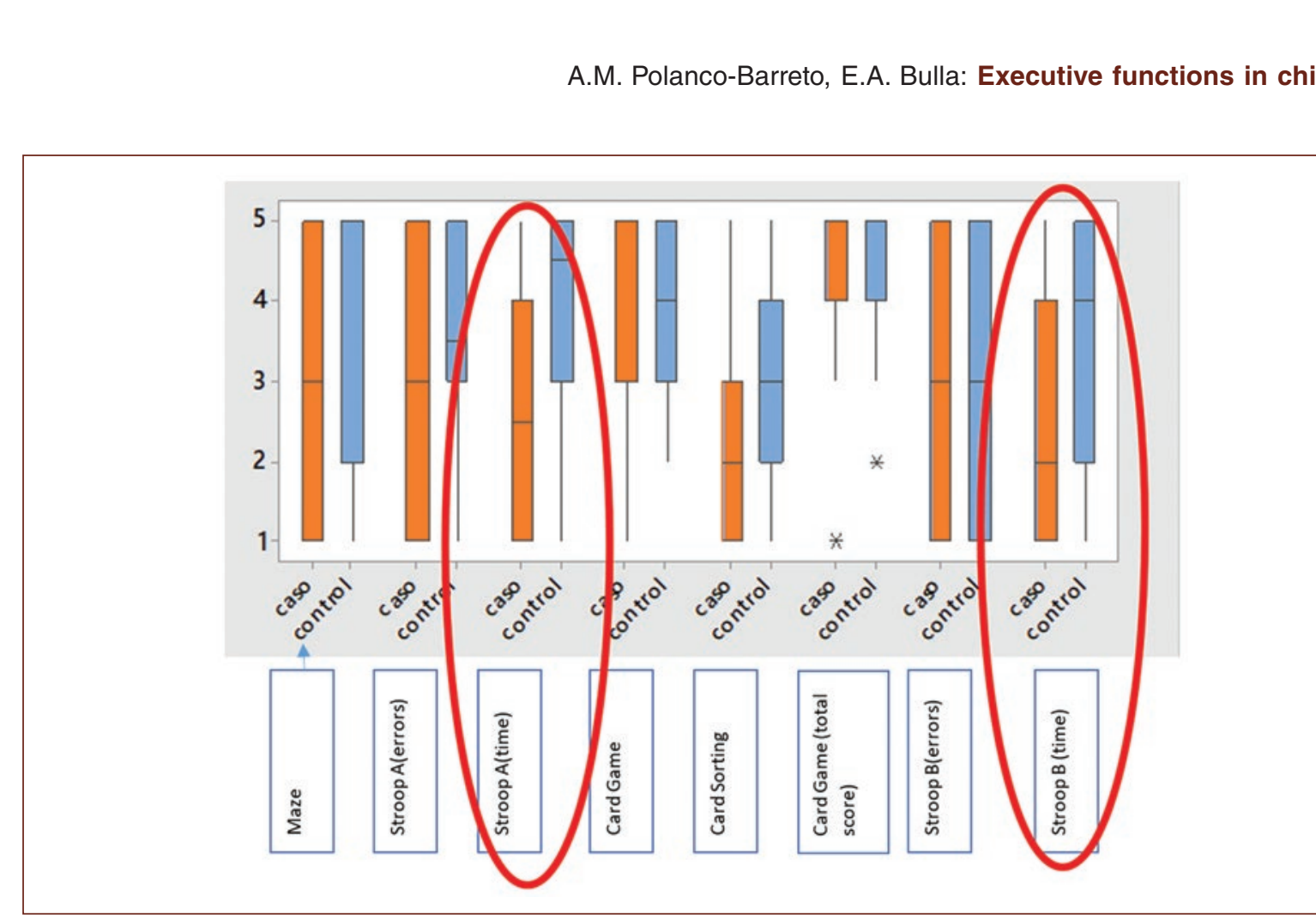

Figure 1. Box plot by orbit medial groups - comparative control case.

behavior) and dorsolateral (measures planning, organization, and classification) subscales/subsets.

The following (Table 1) will show the neuropsychological tests used.

This way, descriptive statistical analysis and association analysis were generated in the results. To do this, the data obtained were rigorously organized in a dynamic table designed in Excel, to favor statistical analysis. In addition, statistical programs such as Minitab and office tools such as Excel were used (since it also has relevant tools for data analysis).

\section{Results}

Evaluation and process was made in general to 71 students ( 43 girls and 28 boys) between 8 and 14 years. The established protocol and in general the entire procedure of neuropsychological characterization were applied. From the analysis of the results, it has been identified that the distribution of the sample, taking into account that it is an association study, is given as follows: about $44 \%$ were cases and $56 \%$ were controls.

Part of the process is to identify and shows differences and possible associations between the two groups (case-control) to determine if it is global or if there are important differences between them. To do this, within the processing of statistical data the following have been
Table 1. Neuropsychological tests used

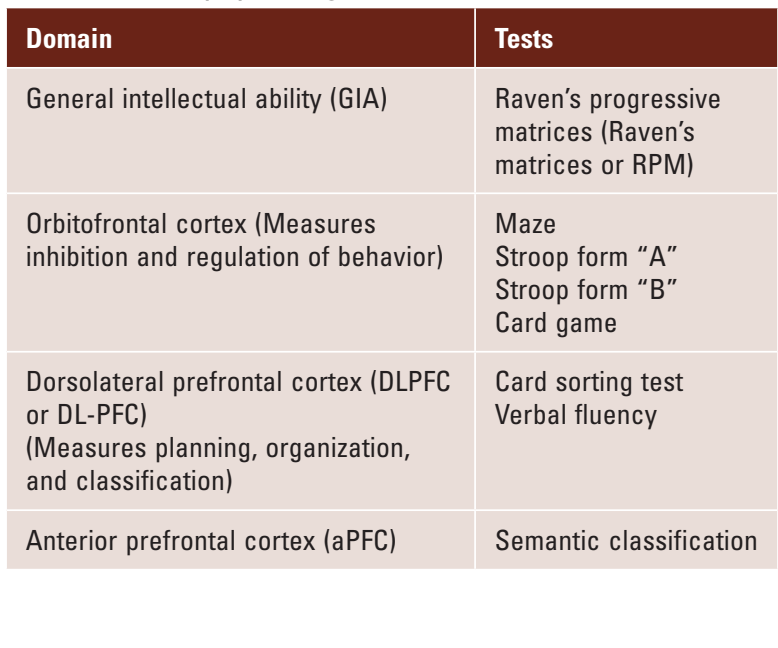

established: at a general level make box plots to identify the distribution and concentration of data and to identify the quartiles, since it is important to remember thatthis is done between quartiles 1 ad 3 (Q1 and Q3), and quartile 2 (Q2) is the median, that is, half of the data: Fhe results by structural area are the following:

Although differentiated data are identified between the two groups, the control group shows greater functionality at a general level, the differences are not so marked. From the results shown in figure 1, greater diferencial process is evidenced in the resultss of Stroop form A and Stroop form B, both in time management. 


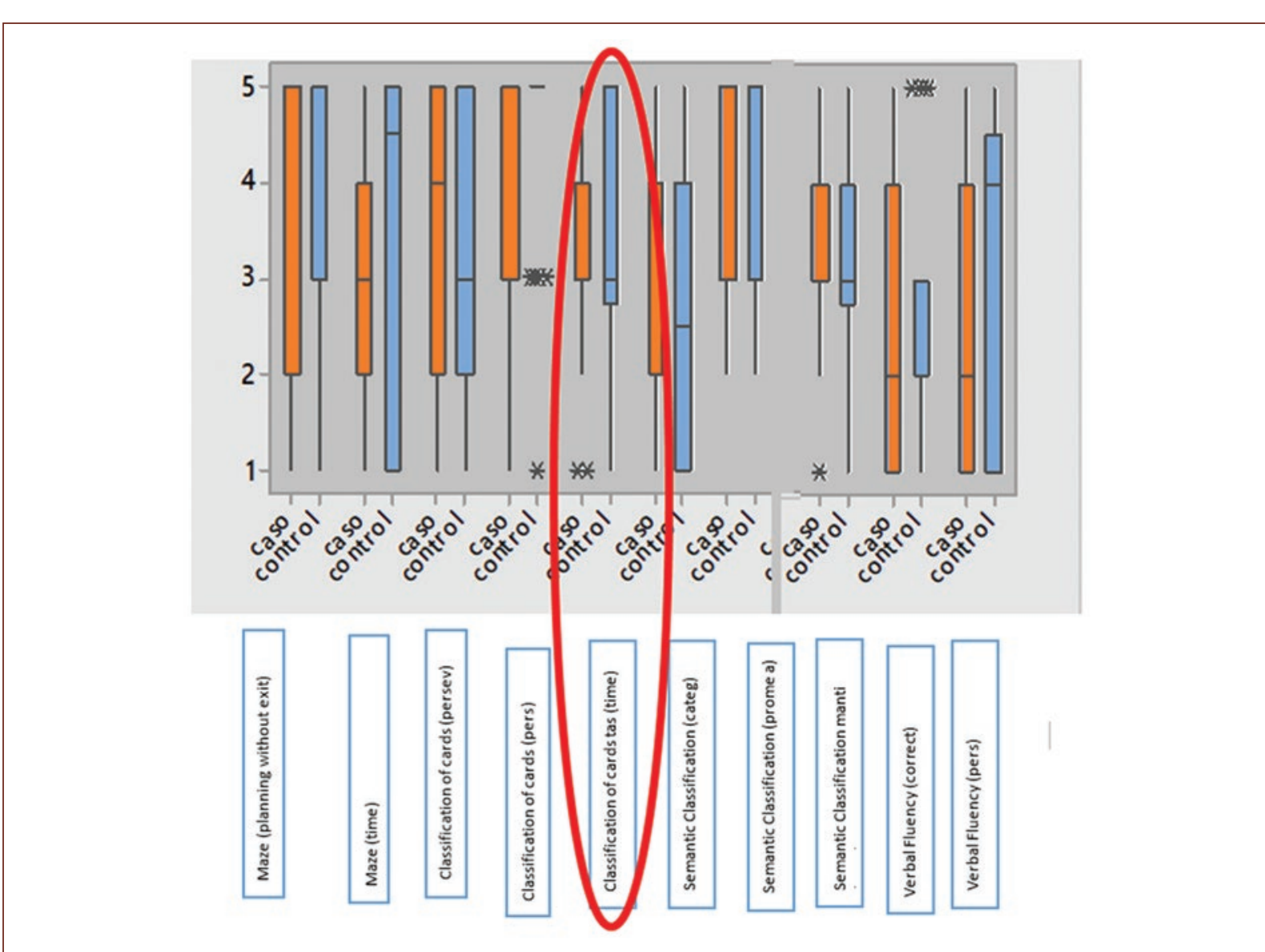

Figure 2. Box plot by dorsolateral groups - comparative control case.

Likewise, at the dorsolateral level, the same process with the applied tests took place, and there is no evidence of marked differences regarding results, except for classification of letters and time management. These results are evidenced in figure 2.

However, Pearson's Chi-squared test is carried out for association, which is a statistical process that denotes the existence of a statistically defined relationship between two variables. Now, in Chi-squared $p$ value, fixed by convention in 0.05 , means that the value should be less than this to be considered an association since it shows that the probability of a phenomenon occurring randomly is minimal. After performing the analysis, it was possible to identify where this association exists in both orbitomedial and dorsolateral, that is, table 2.

In general, the significance of the data shows that the association takes place in time management. As seen in Figure 3, all are associated with time management, with orbitomedial functions being closer.
Table 2. Statistics - Chi-squared probability ratio

$$
\text { Test }
$$

p-value case group

Orbitomedial - Stroop A (time)
Orbitomedial - Stroop B (time)
Dorsolateral classification by (time)

\section{Discussion}

According to what is shown in the results section, it is possible to see how executive functions present differentiated ranges between the control group and the analysis group. This posits differences in the way in which performance of brain activity presents itself among the different participants of the study, "with grouping of the data in box plots which allows to evaluate the integration of executive functions of the Orbitomedial and the dorsolateral cortex. It is also possible 


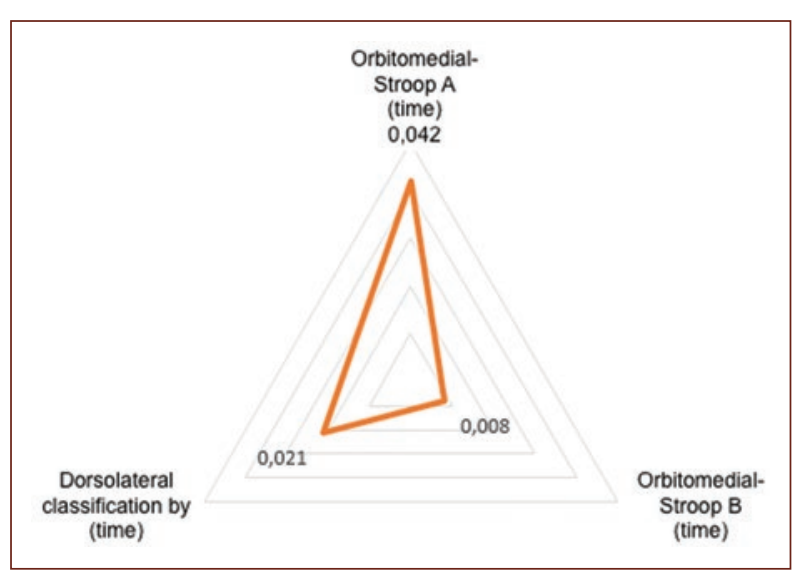

Figure 3. $\mathrm{P}$ value of greater significance.

to see the way executive functions behave according to different objectives or specific tasks, and therefore transfer these findings to the way in which the behavior operates in natural environments.

From this description, it can be inferred that the functionality and maturity of the orbitomedial and dorsolateral cortex are vital for normal evolutionary development and for more complex tasks such as decision-making, problem-solving, and decision-making advocated pragmatic adaptation of the individual to his/her social context. This can be seen in the application of subtests such as Stroop A and B in comparison with the control group and analysis group, since significant differences are evidenced primarily in time management because in unnoticed conditions inhibitory control is required as well as processing speed and cognitive flexibility, to escape previously established automatisms. It is a product of development and maturation of the orbitomedial cortex, which means that this is associated with the possibility of regulating, planning and modulating each step of behavior ${ }^{21}$.

In the same way, another relevant analysis in the development of executive functions and the detected findings is oriented to the regulatory function of language; this seen from behavior control and direction with the help of language-oriented toward a specific goal and toward obtaining reinforcers in the natural context $^{22}$. Significant differences can be detected among the application of subtests such as semantic classification, where a higher performance is observed in the control group compared to the study group; although this quality belongs to the dorsolateral cortex, cold executive functions that involve planning, among others $^{21}$. Development and maturity of the OFC and ventromedial PFC are necessary, since it will depend to a great extent on inhibitory control and the cognitive processes involved in semantic classification tasks such as sustained attention; processing speed, cognitive flexibility, semantic memory, working memory, rand the ability to suppress inappropriate responses - the latter oriented to the orbitomedial PFC ${ }^{23}$.

In this order of ideas, Marino et al. (2011) reported that the pragmatic functionality of executive control- in charge of the prefrontal lobe in general terms - isforiented to perform an active search for the phonological and semantic fields for adequate and meaningful production of language, and its adaptive systematic correlation with the social environment. For this reason, inhibitory control that allows inadequate answers at the time of pragmatic production of language is necessary $^{24}$, as it was previously mentioned.

On the other hand, the mastery, maturity, andedevelopment of the orbitomedial PFC could explain factors related to school failure and alterations, dysfunctions or learning disorders ${ }^{24}$, since adverse events in childhood can present variables of analysis on bow brain activity and executive functions take place diuring development in childhood and adolescence, taking into account that the orbitomedial PFC matures from continuous contact with caregivers and social experience. In causality, it would be relevant to analyze these experiences during these years of development as well as the performance in tasks like those presented in this study, where the study group presents a lower performance in the subtests regarding the orbitomedial PFC?.

In agreement, the findings show a lower performance of the study subjects with greater emphasis on añassociation of variables between cerebral activity ofthe orbitomedial cortex (Stroop A and B subtests) and dorsolateral cortex (Semantic Classification subtests). Consequently, it can be inferred that the study group presents lower performance in the card game, which allows to detect that there is less value in relation to risk benefit, and to the selection of behaviors related to uncertain situations ${ }^{21,25}$.

In agreement with the different findings, especially with the study group, it can be discriminated that the fullness and efficacy of executive functions dependent on the dorsolateral cortex will depend on the maturity and development of the orbitomedial cortex. It seems that self-monitoring, the processing and regulation of emotions and emotional states, as well as the regulation and control of behavior, are essential for the development of cold executive functions with greater 
performance such as planning, operational memory, complex problem-solving, and mental flexibility.

\section{Conflicts of interest}

We declare that the authors of this research do not have and have not had conflicts of interest regarding their rights and participation, and both contributed significantly to the development of the research.

\section{Funding}

Corporación Universitaria Iberoamericana is the institution that has financed $100 \%$ of this research.

\section{Ethical disclosures}

Protection of human and animal subjects. The authors declare that the procedures followed were in accordance with the regulations of the relevant clinical research ethics committee and with those of the Code of Ethics of the World Medical Association (Declaration of Helsinki).

Confidentiality of data. The authors declare that they have followed the protocols of their work center on the publication of patient data.

Right to privacy and informed consent. The authors declare that no patient data appear in this article.

\section{References}

1. Papini M. In: Muzio RN, editor. Psicología Comparada, Evolución y Desarrollo del Comportamiento. Mexico: Manual Moderno; 2009.

2. Flores J, Ostrosky F. Neuropsicologia de los lobulos frontales, funciones ejecutivas y conducta humana. Revi Neuropsicol Neuropsiquiaría Neurociencias. 2008;8:47-58.

3. Sanchez J, Roman F. Amigdala, corteza prefrontal y especializacion hemisferica en la experiencia y la expresión emocional. Anales de Psicol. 2004;20:223-40.

4. Llinas R. El Cerebro y el Mito del yo. Bogotá: Norma; 2002.
5. Vázquez P. Proyecciones de la Corteza Prefrontal a los Núcleos Monoamenérgicos del Mescencéfalo: vías y Receptores Implicados. Tesis-Doctoral. Barcelona, España; 2008.

6. Puig V. Tesis de Doctorado: control Reciproco Entre la Corteza Prefrontal y los Núcleos del Rafe. Papel de los Receptores de Serotonina. Barcelona; 2004.

7. Bausela E. Funciones ejecutivas: nociones del desarrollo desde- una perspectiva neuropsicológica. Acción Psicol. 2014;11:21-34.

8. Echavarría L. Modelos explicativos de las funciones ejecutivas. Rev Invest Psicol. 2017;20:237-47.

9. Tirapu J, Cordero $P$, Luna $P$, Hernáez P. Propuesta de un modelo de funciones ejecutivas basado en análisis factoriales. Rev Neurol. 2017;64:75-84.

10. Spikman JM, Kiers HA, Deelman BG, van Zomeren AH. Construct validity of concepts of attention in healthy controls and patients with $\mathrm{CHI}$. Brain Cogn. 2001;47:446-60.

11. Ramirez B, Romero G. Efectos de la Deprivación Aguda y Repetitiva de Sueño Sobre las Diferentes Modalidades de Atención Según el Modelo Planteado porSolhlber y Mateeren Estudiantes Universitarios de Primer Semestre de Medicina de la Pontificia Universidad Javeriana. Bogotá;2010.

12. Torterolo $P$, Vanini $G$. Nuevos conceptos sobre la generación y el mantenimiento de la vigilia. Rev Neurol. 2010;50:747-58

13. de la Miyar CA, Moes E. Epistemological perspectives in the scientific study and evaluation of executive function. Acta Colomb Psicol. 2014;17:69-79.

14. Ríos M, Muñoz J, Lapedriza N. Alteraciones de la atención tras dãño cerebral traumático: evaluación y rehabilitación. Rev Neurol. 2007;44:291-7.

15. Díaz J, Tirapu J. Aproximación a un modelo neuropsicológico explícativo de los trastornos mentales basado en los síndromes de desconexión. Cuad Neuropsicol. 2017; 11:42-55.

16. Goldberg E. The Executive Brain. Frontal Lobes and the Civilized Mind. Oxford: Oxford University Press, Inc.; 2001.

17. Álvarez F, Brarda G, Calvano M, Del Carril A, Lueiro L, Nazara C, et al. Cruses Entre Psicoanálisis y Neurobiología. Buenos Aires: Lugar editorial S.A; 2011.

18. Delgado M, Etchepareborda M. Trastornos de las funciones ejecutivas. Diagnóstico y tratamiento. Rev Neurolol. 2013;57:95-103.

19. Dumontheil I. Development of the social brain during adolescence. Psicol Educ. 2015;21:117-24.

20. Mah L, Arnold M, Grafman J. Alteración de la percepción social relacionada con las lesiones de la corteza prefrontal. Am J Psychiatry. 2004:7:540-8.

21. Flórez R, Pacheco MC, Rodríguez IA, Güechá CM, Bohórquezz $S M$, Vanegas $\mathrm{CP}$, et al. Habilidades metalingüísticas operaciones metacognitivas y su relación con los niveles de competencia en lectura y escritura: un estudio exploratorio. Forma y Función. 2005:18:15-44

22. Soriano Á, Meza E, Valencia F, Zarate A. Personalidad antisócial o síndrome orbitofrontal. A propósito de dos casos clínicos. Rev Neurol Neurocir Psiquiatría. 2003;36:131-7.

23. Zanin L, Ledezma C, Galarsi F, De Bartoli M. Fluidez verbal en una muestra de 227 sujetos de la región Cuyo (Argentina). Fundam' Hum. 2010;21:207-19.

24. Marino J, Acosta A, Zorza J. Control ejecutivo y fluidez verbal en población infantil: médidas cuantitativas, cualitativs y temporales. Interdisciplinaria. 2011;28:245-60.

25. Grañana N, Richaudeau A, Gorriti CR, O'Flaherty M, Scotti ME Sixto L, et al. Evaluación de déficit de atención con hiperactividad: la escala SNAP IV adaptada a la Argentina. Rev Panam Salud Publica. 2011;29:344-9. 